\title{
SUPERIOR PERFORMANCES OF DIFFERENT NEW MULTILEVEL INVERTER TOPOLOGY WITH DISPARATE PULSE TECHNIQUES
}

\author{
D Karthikeyan, Premkumar P, Sandeep Kumar Prasad, K Selvakumar and \\ R Palanisamy \\ Department of Electrical and Electronics Engineering \\ SRM Institute of Science \& Technology, Kattankulathur, Tamil Nadu, India
}

\begin{abstract}
This paper establish the Analysis\& designing of a new multilevel inverter topology with reduced number of DC source and power switches and further comparing using PWM technique. Through various PWM techniques like NLT, PD, POD and APOD, Comparison is 31 level multilevel inverter using various PWM technique to analysis there characteristics. The analysis PWM technical configured with Vrms, Irms with high efficient, less THD harmonic profile and cost efficient. The nearest level modulation technique is introduced with different DC offset value to evaluate the voltage harmonic at the load. The validation is done for presented PWM technique by using simulation software MATLAB/Simulink and laboratory based experimental test.
\end{abstract}

Key words: NLT, PD, POD and APOD.

Cite this Article: D Karthikeyan, Premkumar P, Sandeep Kumar Prasad, K Selvakumar and R Palanisamy, Superior Performances of Different New Multilevel Inverter Topology with Disparate Pulse Techniques, International Journal of Electrical Engineering and Technology, 11(4), 2020, pp. 80-93.

https://iaeme.com/Home/issue/IJEET?Volume $=11 \&$ Issue $=4$

\section{INTRODUCTION}

Now a days the energy requirement is increasing due to the industry and consumer requirement as increased because of that energy generation as start to move towards the renewable energy like wind, solar etc this is the reason inverter and converter as been playing a big role in converting DC into AC current With the expansion independency on sustainable power source, there is a tremendous increment in the accessibility of segregated DC power sources. This DC power sources can be associated in arrangement or corresponding to expand the voltage level or current ability. The DC power created is to be changed over to AC source because of the transcendence of AC hotspot for transmission and family application .Through using MLI asymmetrical function we can able to reduce the switches and sources by designing the new switching positions and source arrangements by using this method various level can achieve like 7,9,15 and 31-level through various pwm topology like NLT,PD,POD 
and APOD through using the novel multilevel inverter method high THD, low efficiency as been overcome easily and help to achieve high efficiency. In phase disposition the carrier wave as the same path and in same direction, phase opposite disposition the carrier wave as change the path after each 180 degree, In alternative phase opposite disposition as change the carrier signal path in each cycle. The supply voltage as been given to the multi level inverter (MLI) as been control through this above PWM techniques.

\section{EXISTING TOPOLOGY}

\subsection{Seven Level Inverter}

The seven level inverter shown in Fig 1 and the existing topology with various asymmetric PWM technique for this nearest level technique is used it as work using different DC offset value by changing the DC value by comparing with the reference value with two different DC source as 100v and 200v and six switches as been used S1,S2,S3,S4,Sa and Sb where the switching operation as been given clearly in table and the load resistor as been connected parallel to the switches.

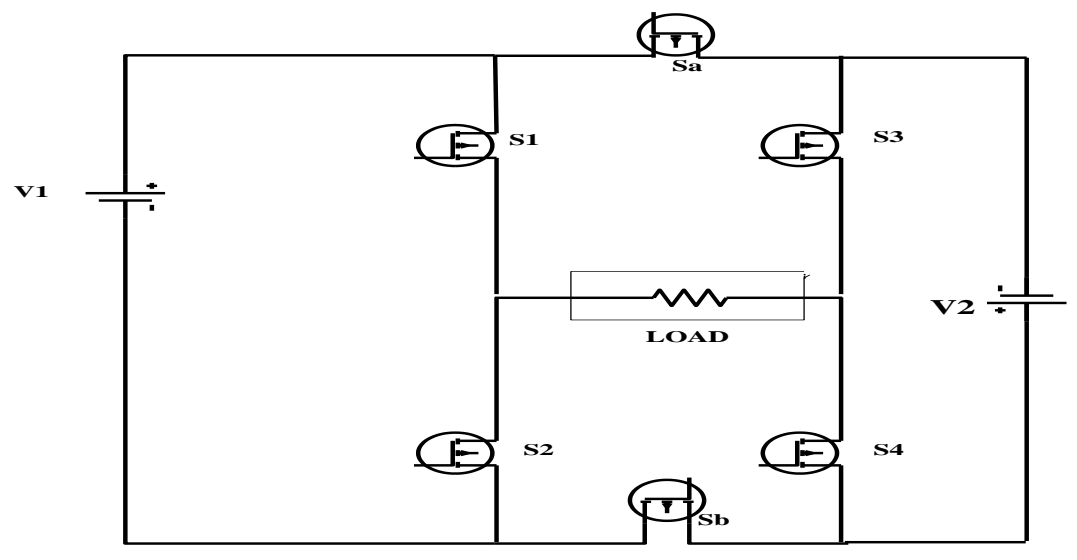

Figure 1 Circuit diagram of 7- level inverter

The switching topology of several level inverter as been shows the function which the operation of each switches in both ON and OFF for both positive and negative switching operation given in table $1 . \&$ Fig 2.

Table 1 for 7- level switching operation

\begin{tabular}{|c|c|c|c|c|c|c|}
\hline S1 & S2 & S3 & S4 & Sa & Sb & Digital \\
\hline 1 & 0 & 0 & 1 & 0 & 1 & 100 \\
\hline 0 & 1 & 1 & 0 & 0 & 1 & 110 \\
\hline 1 & 0 & 1 & 0 & 0 & 1 & 111 \\
\hline 0 & 1 & 1 & 0 & 1 & 0 & 100 \\
\hline 1 & 0 & 0 & 1 & 1 & 0 & 110 \\
\hline 0 & 1 & 0 & 1 & 1 & 0 & 111 \\
\hline
\end{tabular}

The seven level simulation waveform for the final AC output voltage with the peak voltage of $300 \mathrm{v}$ in the time period of $0.1 \mathrm{sec}$ where time in sec as $\mathrm{X}$-axis and voltage $(\mathrm{V})$ as $\mathrm{Y}$ axis. 


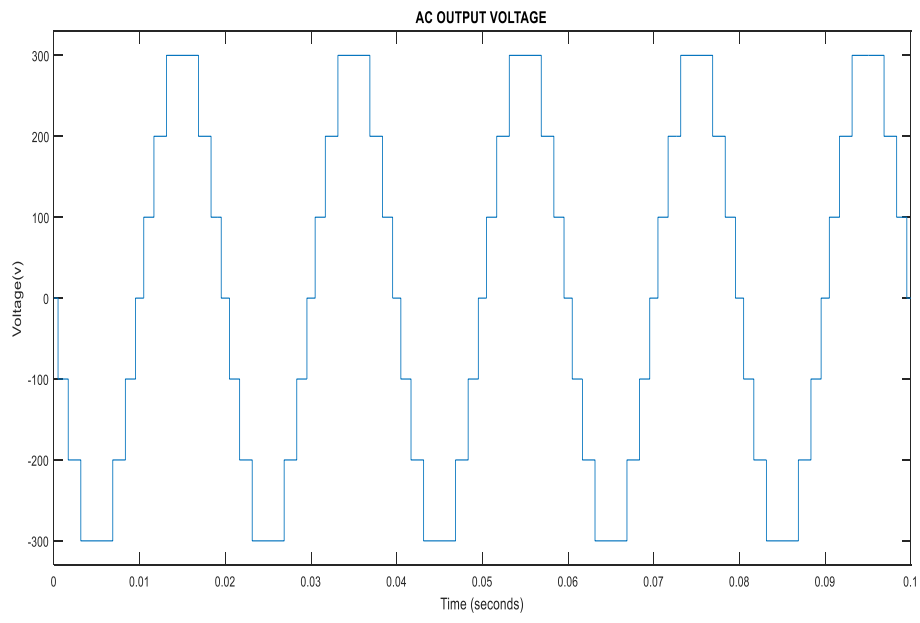

Figure 2 level output waveform

The testing for THD represented in fig 3 is done by selected signal of generated 5 cycle this FFT analysis is done for 3 cycle seven level switching waveform with the frequency of 305.8 to the THD $=12.31 \%$ based on the frequency of $50 \mathrm{~Hz}$ to the maximum frequency of $2500 \mathrm{~Hz}$ range the peak voltage of $300 \mathrm{v}$ in positive half and $-300 \mathrm{v}$ in negative half cycle where the 0 is the start time point. This is 7-level in using the nearest level technique through the various dc offset value of 0.5 to 3.5 in positive and -0.5 to-3.5 in negative cycle.
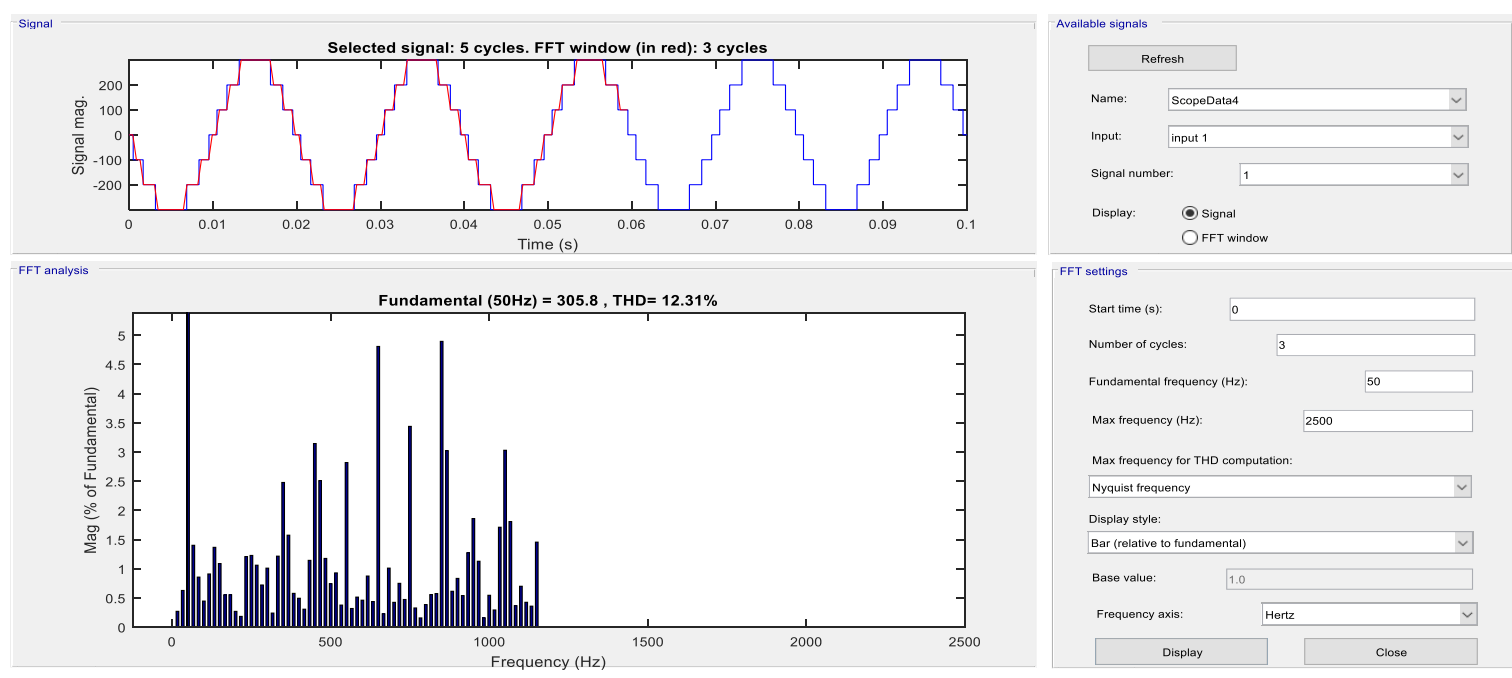

Figure 3 THD for 7-level inverter using NLT

\subsection{9 - Level Inverter}

The nine level inverter as been used existing topology with various asymmetric pwm technique for this nearest level technique is used it as work using different DC offset value by changing the DC value by comparing with the sin wave value with three different DC source as 100v,100v and 200v and eight switches as been used S1,S2,S3,S4,S5,S6,Sa and Sb where the switching operation as been given clearly in table and the load resistor as been connected parallel to the switches through the nine level inverter we can reduce the THD total harmonic distortion is improve and reduce the THD this circuit as extra two then the 7-level this switches are represented S5 and S6 this as connected in between the dc source V1 and V3 this as the voltage of $100 \mathrm{v}$ and $200 \mathrm{v}$ respectively. 


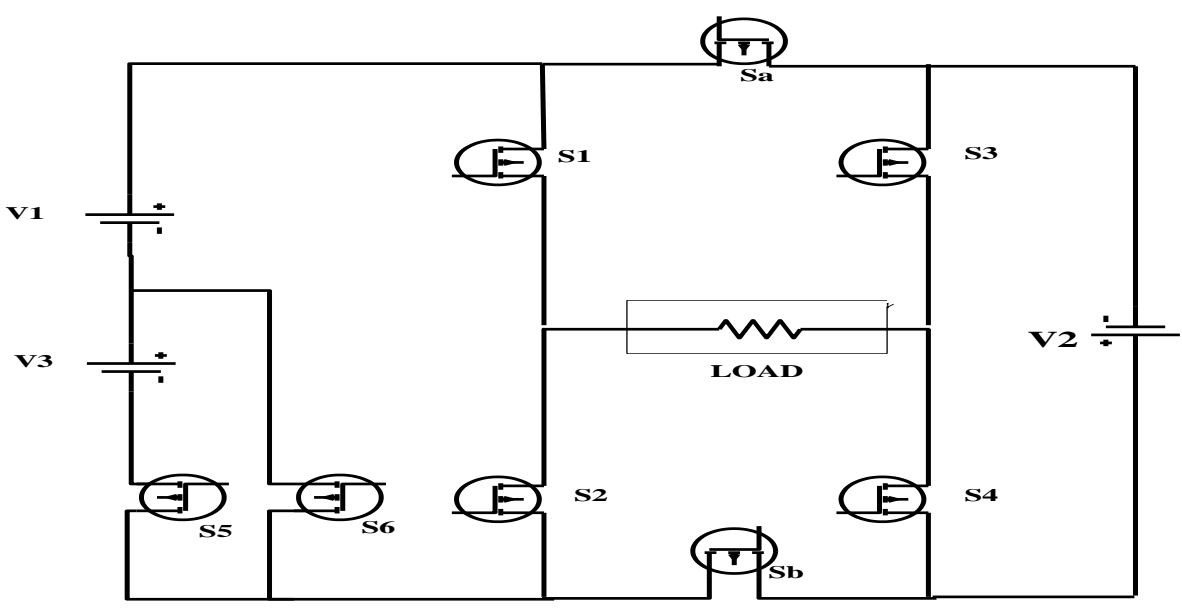

Figure 4 Circuit diagram of 9-level inverter using NLT

The Ac output voltage for the 9-level inverter (shown in fig 4) is 400v in the positive half cycle and $-400 \mathrm{v}$ in the negative half cycle this as the dc offset of 0.5 with the $100 \%$ modulation index this as each pulse stand for 100 volt each cycle complete in the time period of 0.02 . This as voltage $(\mathrm{V})$ as a $\mathrm{X}$-axis then time(sec) as a $\mathrm{Y}$-axis.

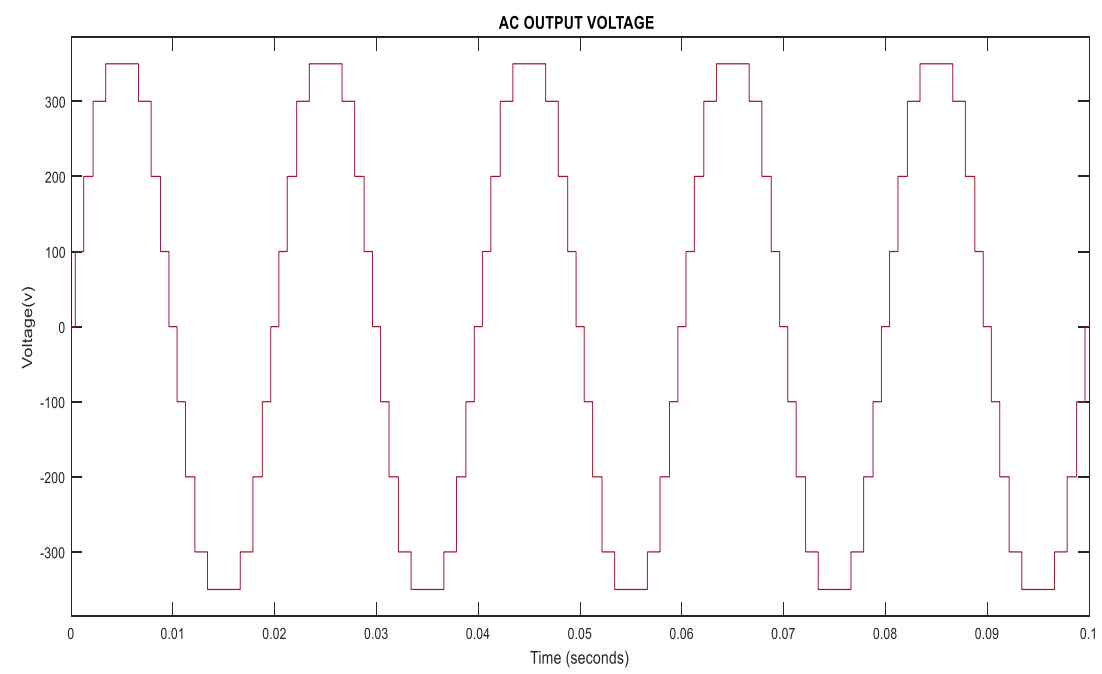

Figure 5 9-Level output waveform

The testing for THD is done by selected signal of generated 5 cycle this FFT analysis is done for 4 cycle nine level as shown in the fig $5 \&$ switching waveform with the frequency of 378.1 to the THD $=9.90 \%$ based on the frequency of $50 \mathrm{~Hz}$ to the maximum frequency of $1000 \mathrm{~Hz}$ range the peak voltage of $400 \mathrm{v}$ in positive half and $-400 \mathrm{v}$ in negative half cycle where the 0 is the start time point represented in the fig 6 . This is 9-level in using the nearest level technique through the various dc offset value of 0.5 to 4.5 in positive and -0.5 to- 4.5 in negative cycle. 


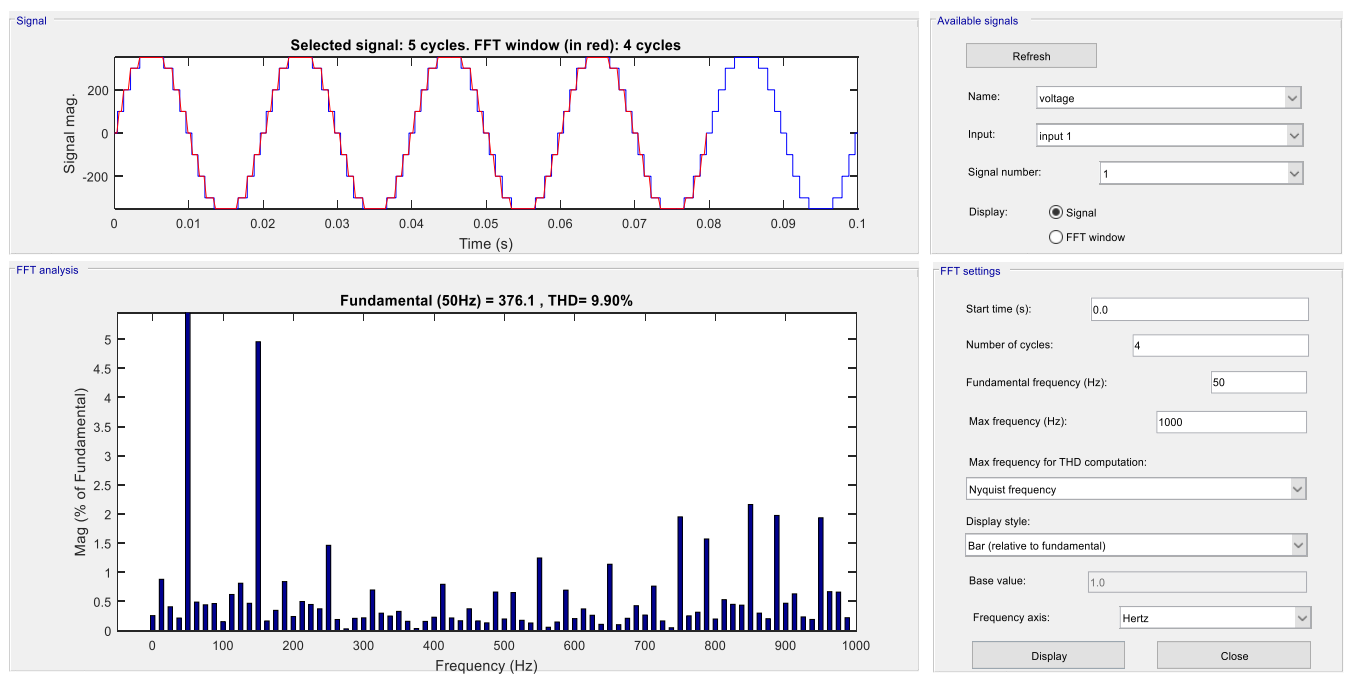

Figure 6 THD for 9- level inverter using NLT

\subsection{Fifteen Level Inverter}

The 15- level inverter as been used existing topology with various asymmetric PWM technique for this nearest level technique is used it as work using different DC offset value by changing the DC value by comparing with the sin wave value with three different DC source as $100 \mathrm{v}, 200 \mathrm{v}$ and $400 \mathrm{v}$ and eight switches as shown in the fig 7 and it has been used $\mathrm{S} 1, \mathrm{~S} 2, \mathrm{~S} 3, \mathrm{~S} 4, \mathrm{~S} 5, \mathrm{~S} 6, \mathrm{~S} 7, \mathrm{~S} 8, \mathrm{Sa}$ and Sb where the switching operation as been given clearly in table and the load resistor as been connected parallel to the switches S1,S2,S3 and S4 through the fifteen level inverter we can reduce the THD total harmonic distortion is improve and reduce the THD this circuit as extra two then the 9-level this switches are represented S7 and $\mathrm{S} 8$ this as connected in between the dc source V1 and V3 this as the voltage of 100v and 400v respectively. This circuit diagram as shown in the fig 7 the voltage V2 is connect in the negative side with the S3 and S4 in the positive side. This IGBT switches are H- bridge connect with the load resistor.

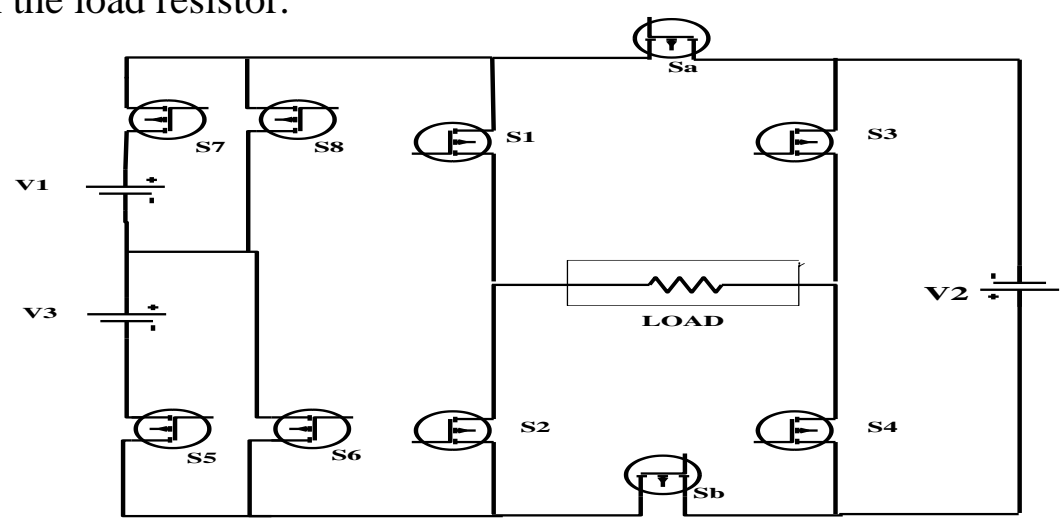

Figure 7 Circuit diagram of 15-level inverter using NLT

In ac output voltage for the 15 -level inverter this as a peak value of $700 \mathrm{v}$ in the positive half cycle and $-700 \mathrm{v}$ in the negative half cycle and one zero pulse this as the dc offset of 0.5 with the $100 \%$ modulation index this as each pulse stand for 100 volt each cycle complete in the time period of $0.02 \mathrm{sec}$. This as voltage $(\mathrm{V})$ as a $\mathrm{X}$-axis then time(sec) as a $\mathrm{Y}$-axis. This waveform as seven positive level and seven negative level is represented in fig 8 . 


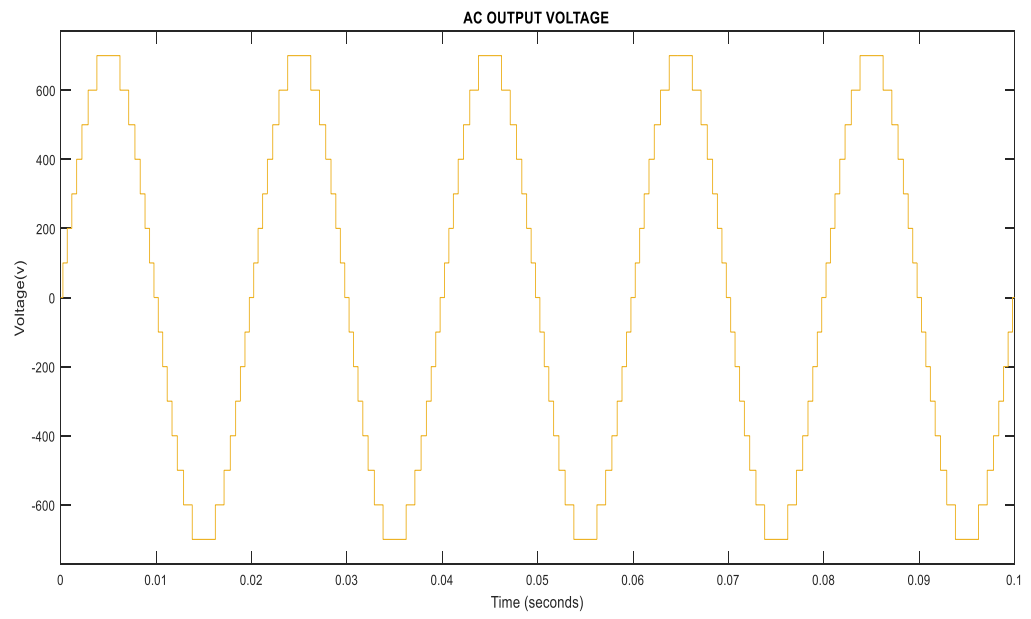

Figure 8 15- level output waveform

The testing for THD is done by selected signal of generated 5 cycle this FFT analysis is done for 4 cycle fifteen level switching waveform as shown in the fig 9 with the frequency of 707.8 to the THD $=5.39 \%$ based on the frequency of $50 \mathrm{~Hz}$ to the maximum frequency of $1000 \mathrm{~Hz}$ range.
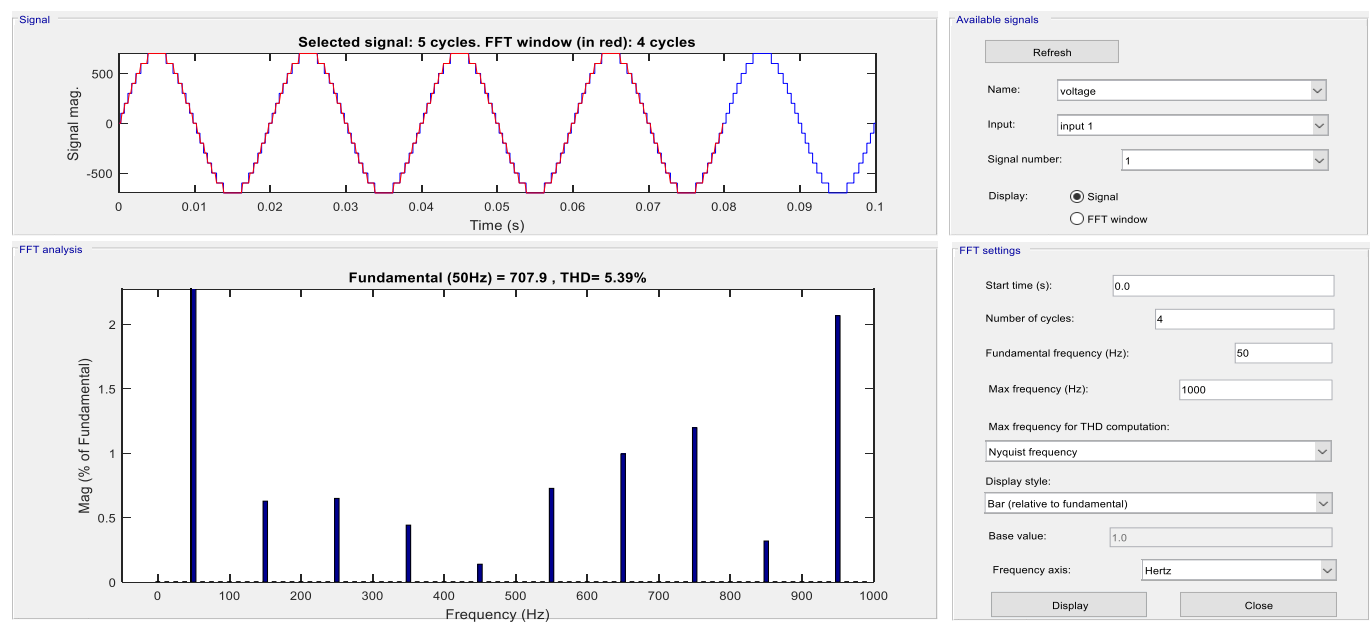

Figure 9 THD for 15 - level inverter using NLT

\subsection{Comparison the Resulted Value with Existing Value}

Through the above techniques the nearest level technique is been compare with the existing topology result from the basic paper by comparing the THD,Irms and Vrms value through this function various value are take from Bhogeswara RaoAngara, M.M.Tripathi "Novel design of cascaded multilevel inverter with reduced number of components"978-1-4673-65406/15/31.00 @2015IEEE . this value are taken for 0.5,0.45,0.4,0.35 etc with the dc offset value this as clearly shows the better result compare with the base paper shown below in the table 2 \& 3 . 
D Karthikeyan, Premkumar P, Sandeep Kumar Prasad, K Selvakumar and R Palanisamy

Table $2 \& 3$ Shows the comparison of RMS value \& THD with the existing topology

\begin{tabular}{|c|c|c|c|c|}
\hline Value & Vrms(new) & Irms(new) & Vrms & Irms \\
\hline $\mathbf{0 . 5}$ & 227.7 & 227.7 & 217.7 & 217.7 \\
\hline $\mathbf{0 . 4 5}$ & 227.9 & 227.9 & 217.9 & 217.9 \\
\hline $\mathbf{0 . 4 0}$ & 228.3 & 228.3 & 218.1 & 218.1 \\
\hline $\mathbf{0 . 3 5}$ & 228.6 & 228.6 & 218.3 & 218.3 \\
\hline
\end{tabular}

\begin{tabular}{|l|l|l|}
\hline Level & THD & THD(new) \\
\hline 7-Level & 11.86 & 11.65 \\
\hline 9-Level & 10.13 & 10.08 \\
\hline 15-Level & 8.18 & 5.39 \\
\hline
\end{tabular}

The THD value for different level is also calculated with the existed only there show the better result in higher level like 15,9 and 7 levels respectively there result are given above which as been compare with the existing topology.

\section{PROPOSED TOPOLOGY}

\subsection{1- Level Inverter Using Different PWM Techniques}

The 31- level inverter as used to reduce the harmonics which as eight switches where four switches are connected series with the four source next to each switches the basic H-bridge as four switches the load resistor as connected with parallel there are four diode connected in series which is help to current flow without any short circuit between the switches there are four DC source DC 1,2,3 and 4 it as the voltage of 24,48,96 and 192 volt. This circuiting is same for PD, POD and APOD used in different PWM techniques mentioned as fig 10 respectively.

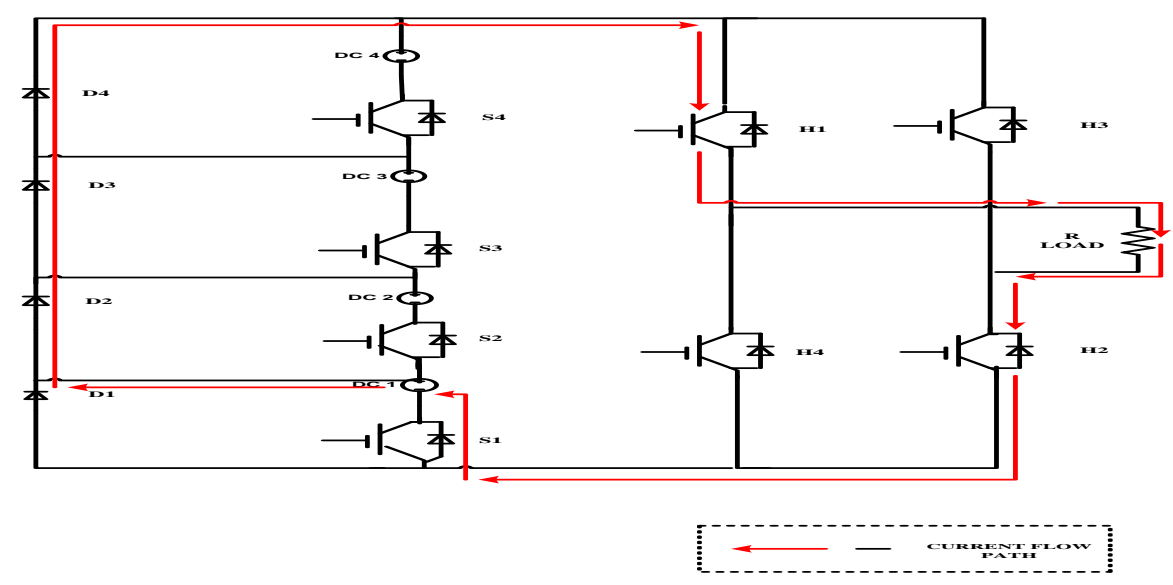

Figure 10 Circuit diagram for 31- level inverter

\subsection{Various PWM Techniques}

PD - This is the one of the method and the techniques and the working principle are shown in the fig 11 in pulse width modulation techniques' which as been comes under the asymmetric PWM signal.Here the carrier signal as above zero they are in the same path.

POD - This is the one of the method in pulse width modulation techniques' which as been comes under the asymmetric pwm signal.Here the phase as been changes after $180^{*}$ degree.

APOD-This is the one of the method in pulse width modulation techniques' which as been comes under the asymmetric pwm signal, The carrier signal change in both positive and negative stages. 


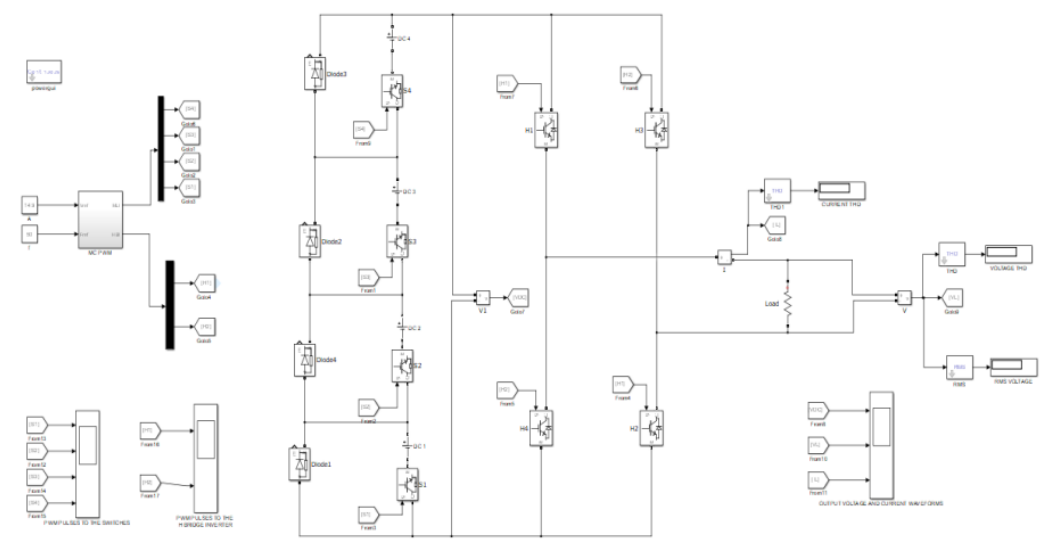

Figure 11 Circuit diagram of 31- level MLI using various PWM

This table 4 shows the digital function of each switches both on and off by denote with the binary digit 0 and 1 switches as some specific function S1,S2,S3 and S4 as continues switching operation but switches $\mathrm{H} 1, \mathrm{H} 2, \mathrm{H} 3$ and $\mathrm{H} 4$ are used from the current flow path during the positive cycle the $\mathrm{H} 1$ and $\mathrm{H} 2$ are in $\mathrm{ON}$ but $\mathrm{H} 3$ and $\mathrm{H} 4$ are in $\mathrm{OFF}$ but in negative $\mathrm{H} 3$ and $\mathrm{H} 4$ are in $\mathrm{ON}$ and the corresponding PD output waveforms are described in the fig 12 $\& 13$ respectively.

Table 4 -31 level inverter switching operator positive cycle

\begin{tabular}{|c|c|c|c|c|c|c|c|}
\hline S4 & S3 & S2 & S1 & H1 & H2 & H3 & H4 \\
\hline 0 & 0 & 0 & 0 & 1 & 1 & 0 & 0 \\
\hline 0 & 0 & 0 & 1 & 1 & 1 & 0 & 0 \\
\hline 0 & 0 & 1 & 0 & 1 & 1 & 0 & 0 \\
\hline 0 & 0 & 1 & 1 & 1 & 1 & 0 & 0 \\
\hline 0 & 1 & 0 & 0 & 1 & 1 & 0 & 0 \\
\hline 0 & 1 & 0 & 1 & 1 & 1 & 0 & 0 \\
\hline 0 & 1 & 1 & 0 & 1 & 1 & 0 & 0 \\
\hline 0 & 1 & 1 & 1 & 1 & 1 & 0 & 0 \\
\hline 1 & 0 & 0 & 0 & 1 & 1 & 0 & 0 \\
\hline 1 & 0 & 0 & 1 & 1 & 1 & 0 & 0 \\
\hline 1 & 0 & 1 & 0 & 1 & 1 & 0 & 0 \\
\hline 1 & 0 & 1 & 1 & 1 & 1 & 0 & 0 \\
\hline 1 & 1 & 0 & 0 & 1 & 1 & 0 & 0 \\
\hline 1 & 1 & 0 & 1 & 1 & 1 & 0 & 0 \\
\hline 1 & 1 & 1 & 0 & 1 & 1 & 0 & 0 \\
\hline 1 & 1 & 1 & 1 & 1 & 1 & 0 & 0 \\
\hline
\end{tabular}

\subsection{PD Output Waveforms}

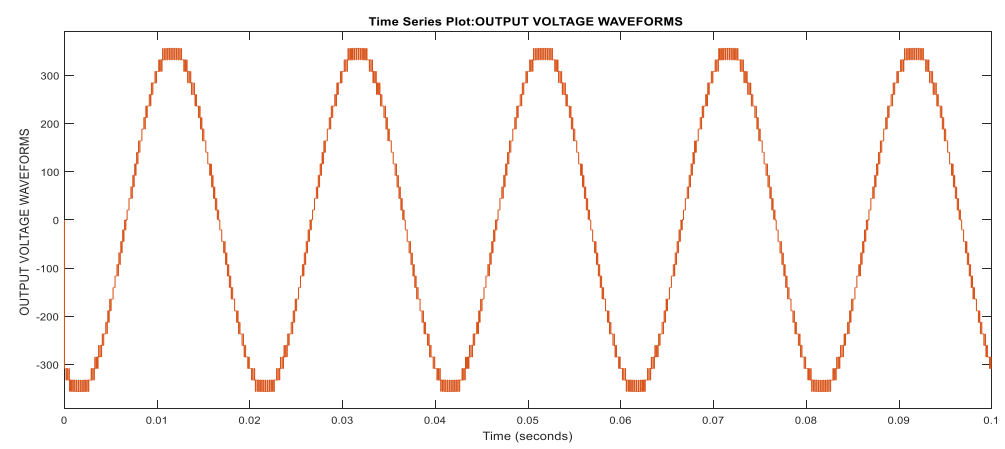


D Karthikeyan, Premkumar P, Sandeep Kumar Prasad, K Selvakumar and R Palanisamy

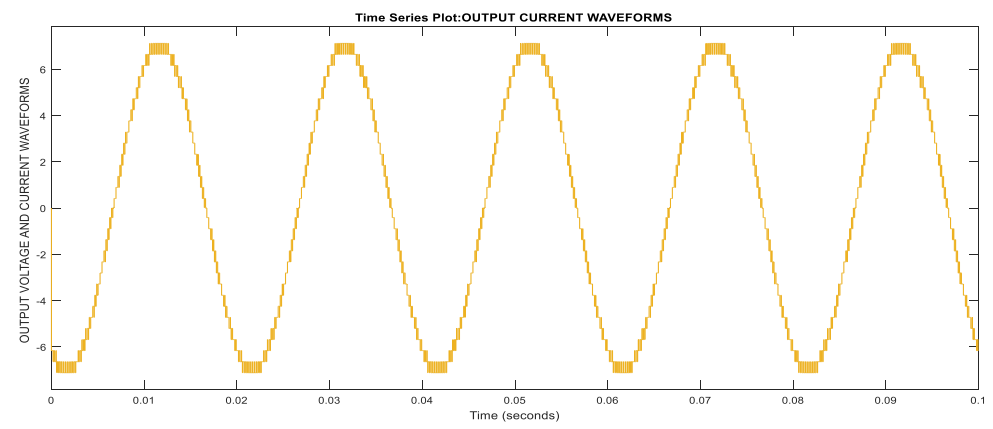

Figure $12 \& 13$ Shows the ac output voltage \& current waveform using PD

\subsection{FFT Analysis of PD}
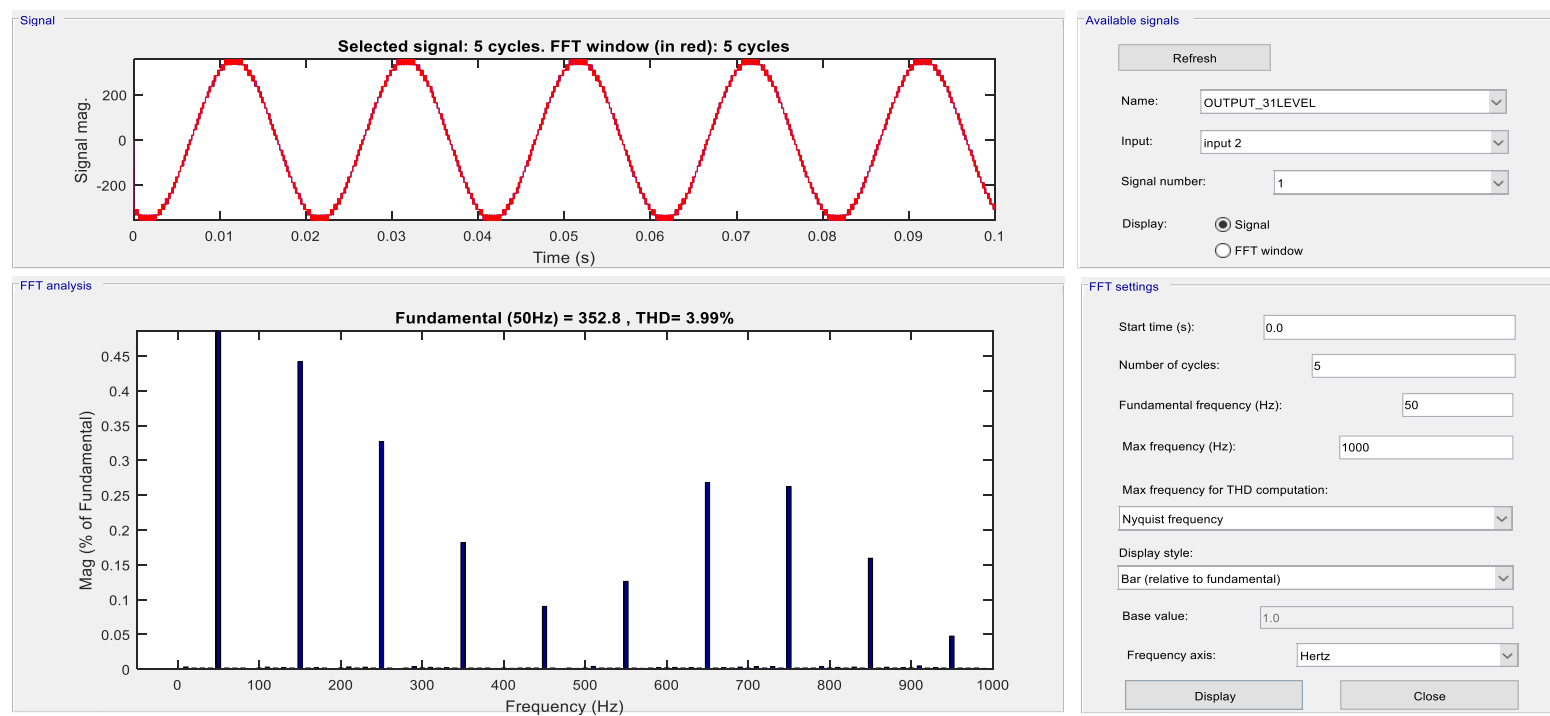

Figure 14 THD analysis for ac output voltage

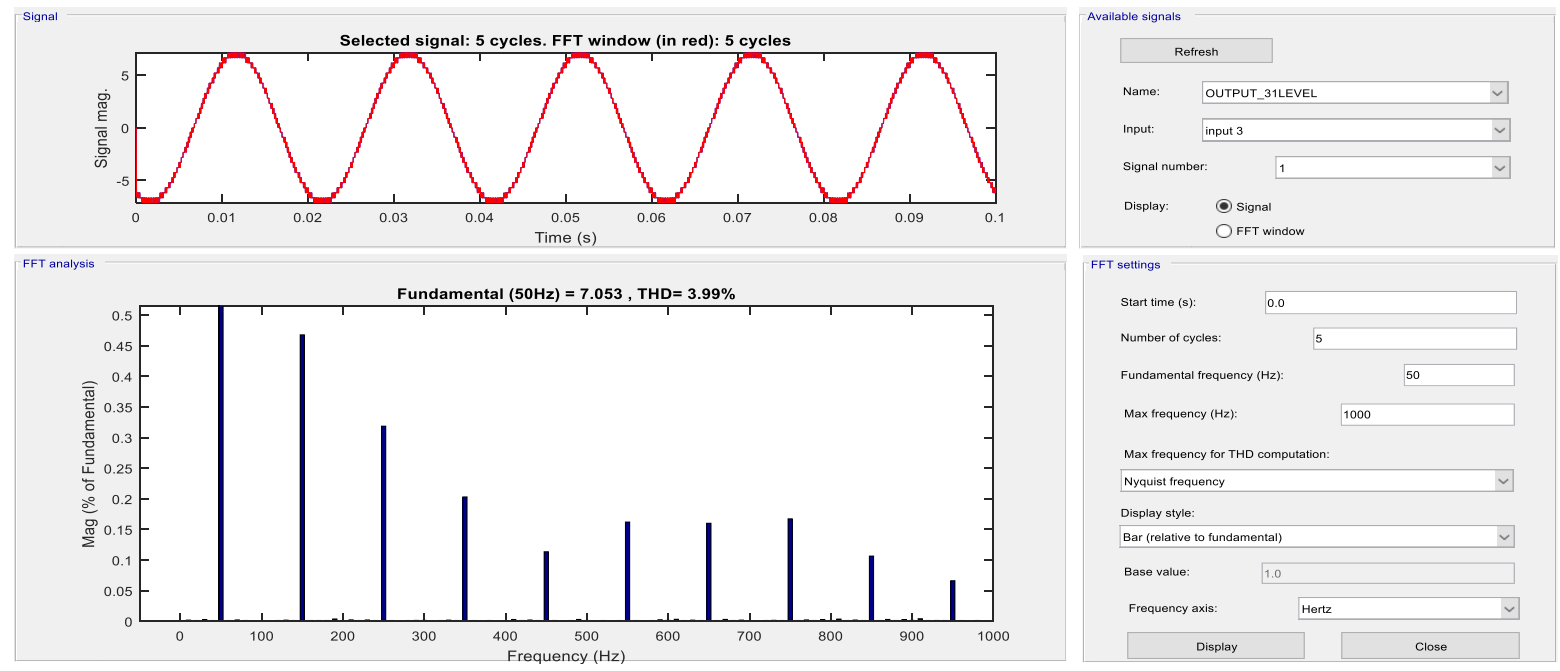

Figure 15 THD analysis for ac output current

The FFT analysis of output voltage and current for the 31 level inverter as been below where the THD of output voltage is $3.99 \%$ at the frequency of $352.8 \mathrm{HZ}$ in the range of $1000 \mathrm{HZ}$ as maximum frequency during the starting period the FFT analysis is maximum 
same for current as the frequency $7.063 \mathrm{HZ}$ as the THD of $3.99 \%$ the peak value as 7 in positive and -7 in negative and the analysis reports are represented in the above fig $14 \& 15$

\subsection{POD Output Waveform}
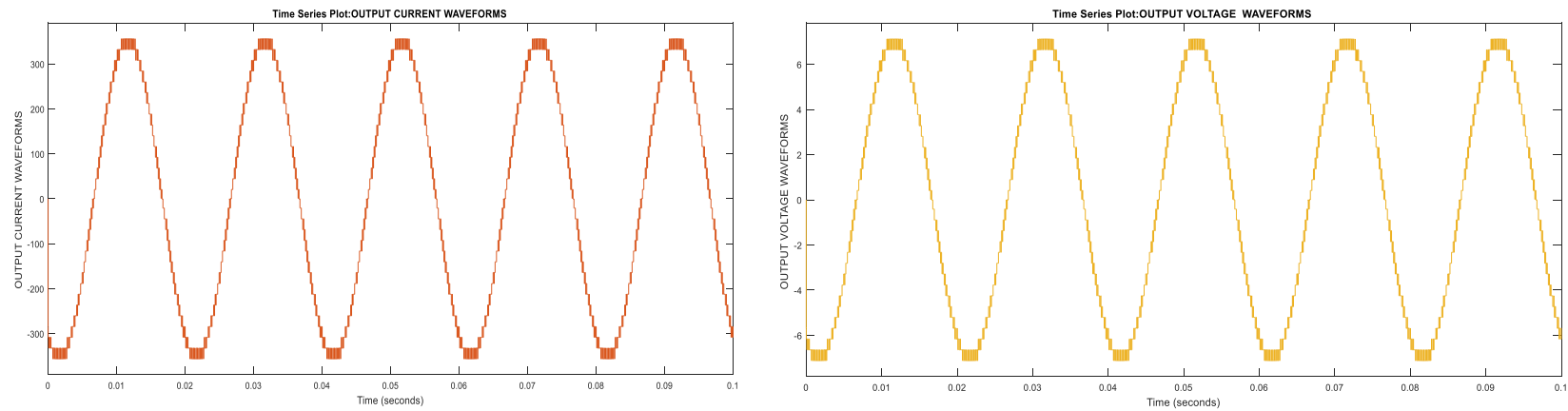

Figure $16 \& 17$ Shows AC output current \& voltage waveform using POD

The current output waveform with $\mathrm{X}$-axis as current (A) and $\mathrm{Y}$-axis as time (sec) which as the peak current of 7A in positive and negative peak current as $-7 \mathrm{~A}$ for a cycle as the time period of $0.02 \mathrm{sec}$ as shown in the fig $16 \& 17$ respectively.

\subsection{FFT Analysis of POD}

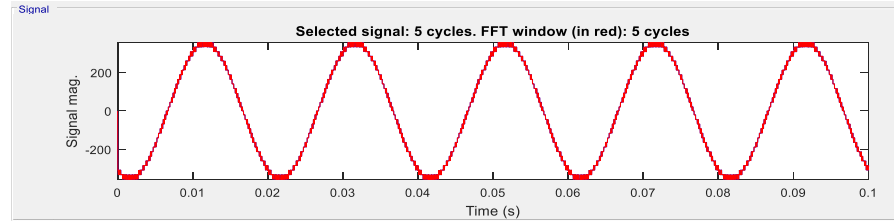

$m$
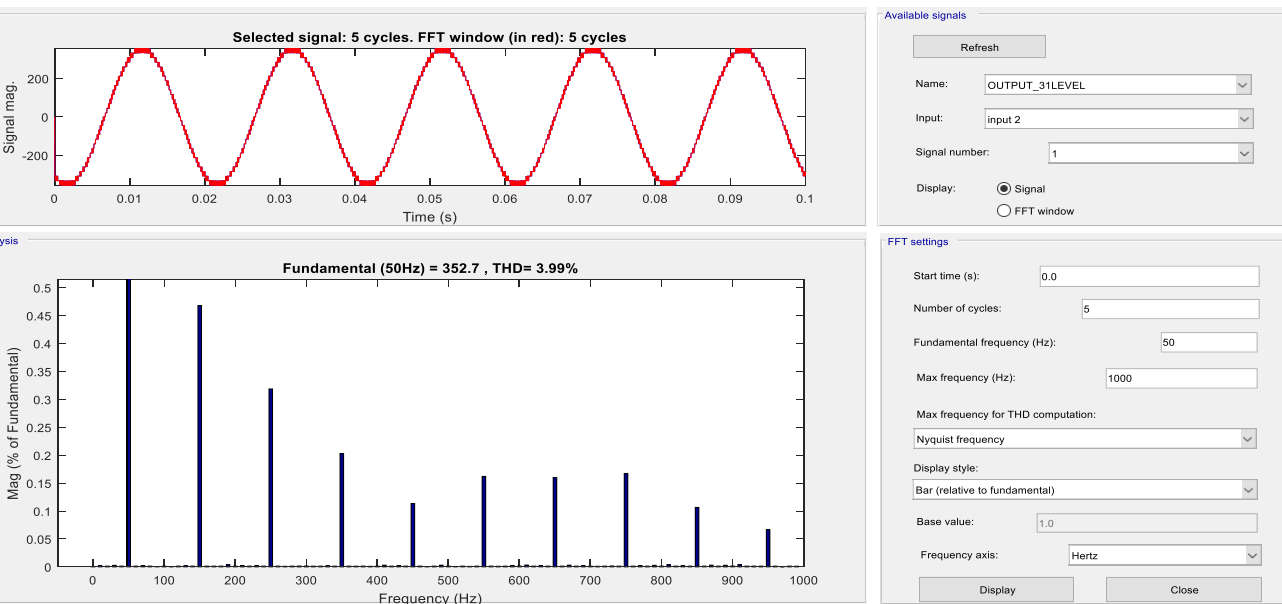

Figure 18 THD analysis for Ac output voltage
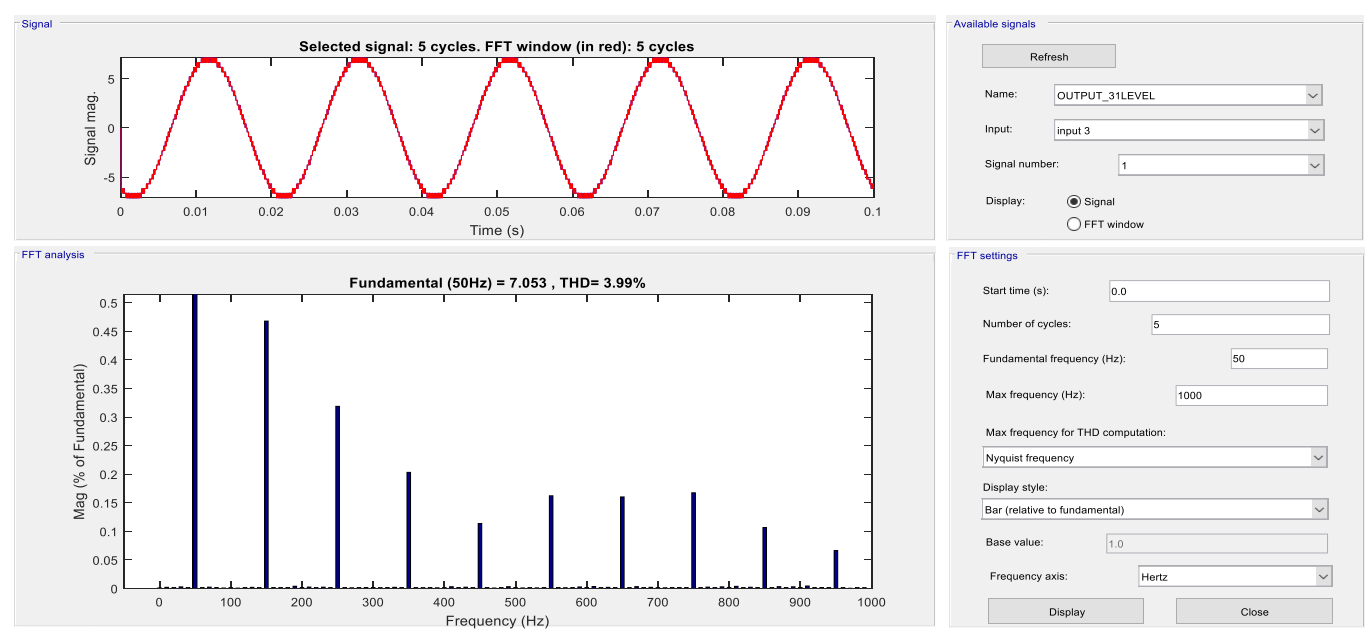

Figure 19 THD analysis for Ac output current 
The FFT analysis of output voltage and current for the 31- level inverter as been below in the fig $18 \& 19$ where the THD of output voltage is $3.99 \%$ at the frequency of $352.8 \mathrm{HZ}$ in the range of $1000 \mathrm{HZ}$ as maximum frequency during the starting period the FFT analysis is maximum same for current as the frequency $7.063 \mathrm{HZ}$ as the THD of $3.99 \%$ the peak value as 7 in positive and -7 in negative respectively.

\subsection{APOD Output Waveform}

\section{AC Output Current \& Voltage}
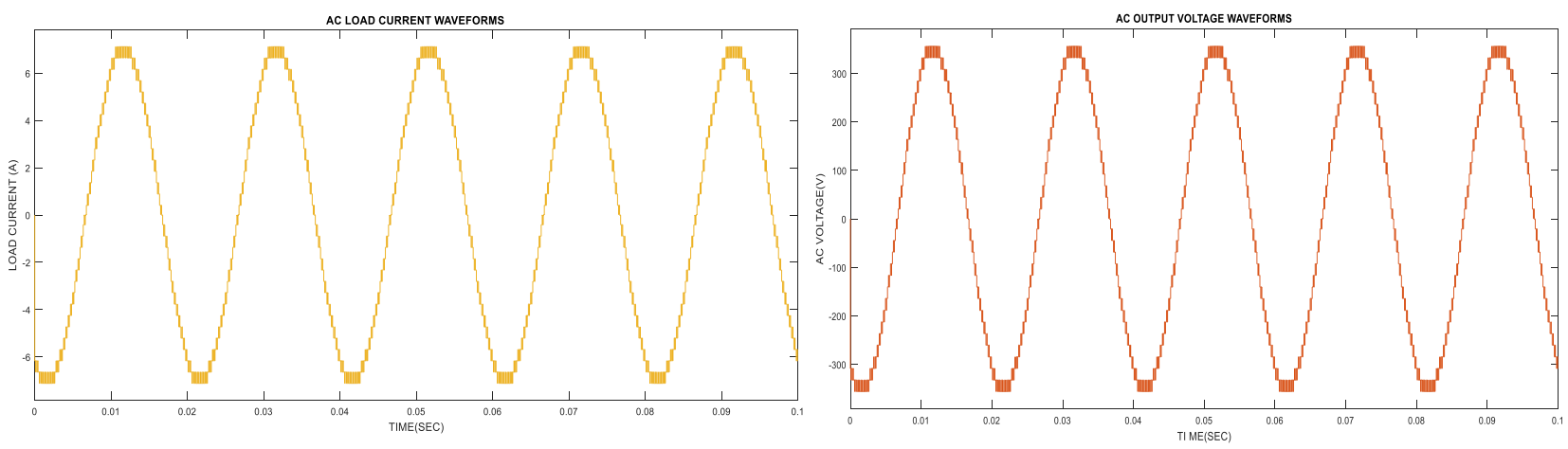

Figure 20 \& 21 Shows AC output current \& voltage waveform

This waveform as output waveform in the fig 20 for the alternative current $\mathrm{X}$-axis as output voltage and Y-axis as time with the peak voltage $360 \mathrm{v}$ at the time duration of $0.1 \mathrm{sec}$ for a complete cycle each cycle as the time duration of $0.02 \mathrm{sec}$ for negative half the peak value is $-360 \mathrm{v}$.

The current output waveform in fig 21 with $\mathrm{X}$-axis as current (A) and Y-axis as time (sec) which as the peak current of $7 \mathrm{~A}$ in positive and negative peak current as $-7 \mathrm{~A}$ for a cycle as the time period of $0.02 \mathrm{sec}$.

\subsection{FFT Analysis of POD}

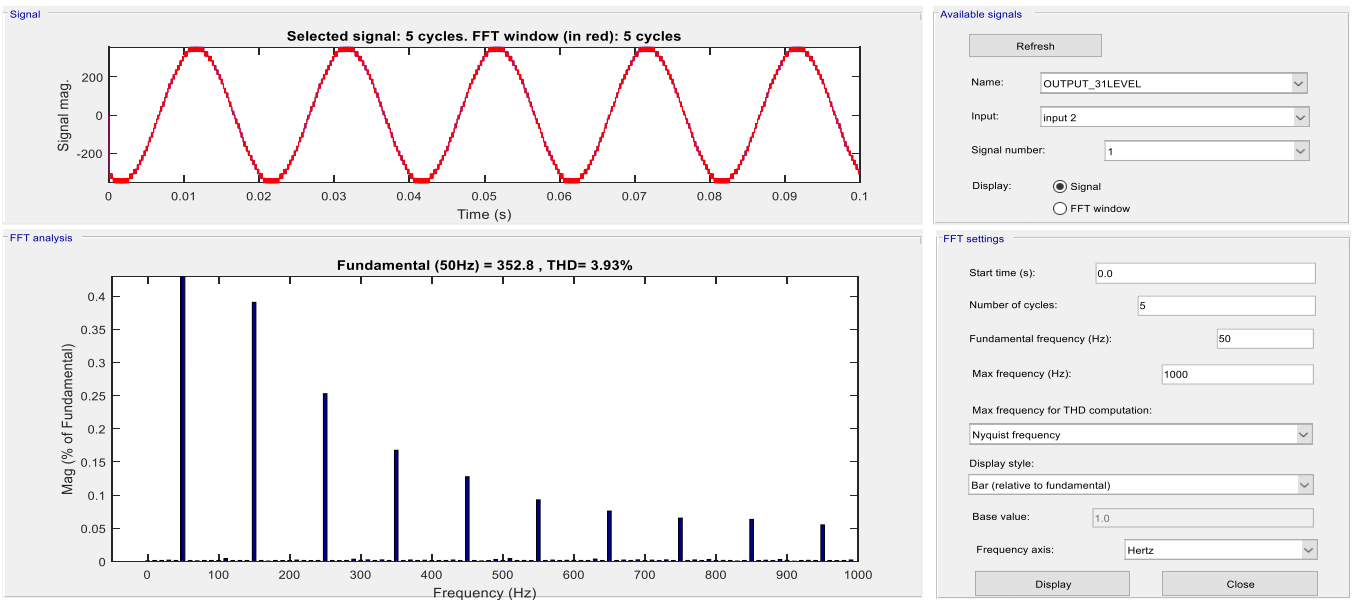

Figure 22 THD analysis of Ac output voltage 


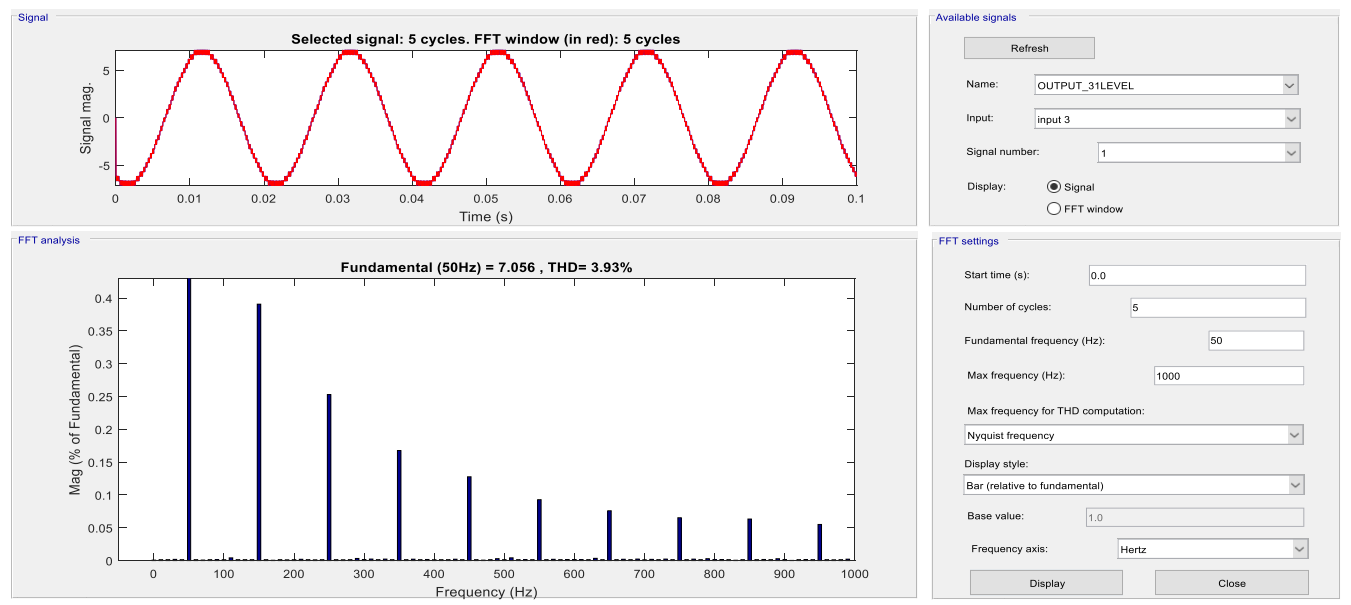

Figure 23 THD analysis of Ac output current

The FFT analysis in fig $22 \& 23$ of output voltage and current for the 31 - level inverter as been below where the THD of output voltage is $3.99 \%$ at the frequency of $352.8 \mathrm{HZ}$ in the range of $1000 \mathrm{HZ}$ as maximum frequency during the starting period the FFT analysis is maximum same for current as the frequency $7.063 \mathrm{HZ}$ as the THD of $3.99 \%$ the peak value as 7 in positive and -7 in negative and the analysis reports represented and the table 5 shows the comparison of existing topology levels.

Table 5 Comparison with the existing topology

\begin{tabular}{|c|c|c|c|c|c|c|}
\hline NAME & THD & THD(EX) & SWITCHES & SWITCHES(EX) & SOURCE & SOURCE(EX) \\
\hline PD & 3.99 & 4.05 & 8 & 10 & 4 & 5 \\
\hline POD & 3.99 & 4.15 & 8 & 10 & 4 & 5 \\
\hline APOD & 3.93 & 4.17 & 8 & 10 & 4 & 5 \\
\hline
\end{tabular}

\subsection{Comparison with the Existing Topology Result}

At the modulation index $100 \%$ this paper as been compare and also having better results with the various level like 7,9 and 15 is also as better THD with the 31 level and it as better value then PD,POD and NLT. The alternative phase opposite disposition is used for hardware implementation due to it as the THD 3.93\% which as been improved for the existing basic paper Shubham Kumar Gupta(1), Kuldeep Rathore(2) and Praveen Bansal(3) "Design and Analysis of a New 31-Level Asymmetrical Inverter Topology with Different PWM Techniques" 978-1-5386-6472-8/18/31.00 @2018 IEEE.

\section{HARDWARE RESULT}

\subsection{Hardware Implementation}

Table 6 Hardware components details

\begin{tabular}{|l|l|l|}
\hline \multicolumn{1}{|c|}{ NAME } & \multicolumn{1}{c|}{ DETAILS } & \multicolumn{1}{c|}{ RANGE } \\
\hline MOSFET & IRF250 & $12 \mathrm{~V}-15 \mathrm{~V}$ \\
\hline MICROPROCESSOR & DSPIC30F2010 & $5 \mathrm{~V}$ \\
\hline IC(PHOTODIODE IC) & TLP250 & $5 \mathrm{~V}-15 \mathrm{~V}(\mathrm{AC})$ \\
\hline VOLTAGE REGULATOR & IC7805 & $5 \mathrm{~V}$ \\
\hline CRYSTAL OSCILLATOR & PLL & $10 \mathrm{mH}-20 \mathrm{Mh}$ \\
\hline TRANSFORMER & Transformer & $230 \mathrm{~V} / 12 \mathrm{~V}$ \\
\hline
\end{tabular}


This hardware has been implemented and the details are shown in table 6. Using alternative phase opposite disposition which as three multi tapped transformer with 7 tapping which is help to converter $230 \mathrm{v}$ into $12 \mathrm{v}$ this switches are operate at the range of 12 to 15 volt which as the micro controller to implement the switching operation and it as different voltage $6,12,24$ and 48 volts for the four dc source to convert the ac source into dc source four diodes are connected in series ask as power source for the MLI the switch as been connected with heat sink to reduce the switching loss and the hardware design for 31-level is shown in the fig 24.
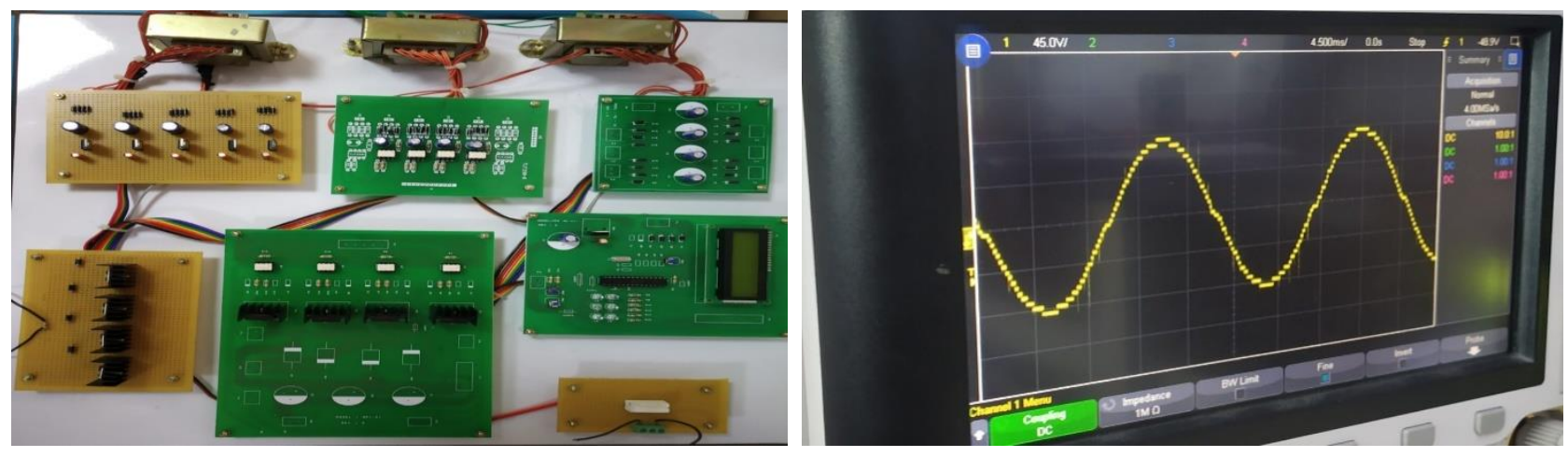

Figure 24 Hardware design for 31-level MLI using APOD Figure 25 Output waveform for ac output voltage and current

\subsection{AC Output Waveform}

This both output waveform of voltage and current with the peak voltage of $46 \mathrm{v}$ and $-46 \mathrm{v}$ in negative it as the better results in fig 25

\section{CONCLUSION}

Here various novel topology has been analysed with different PWM techniques like PD,POD \& APOD and the results are tabulated with various parameters like RMS voltage, current \& THD and its found that new PWM techniques gives better results compared with earlier PWM techniques imposed on the topologies. From this results this PD,POD \& APOD PWM techniques are tested on new design 31- level novel multilevel inverter topology which has advantages' like low power components and enhanced performances like least THD value and better RMS voltage and current at APOD PWM techniques, compare to existing topologies and the results are evident using matlab simulation and validated using hardware output.

\section{REFERENCES}

[1] S. Laali, K. Abbaszades and H. Lesani, (2011) "New Hybrid Control methods based on multi-carrier PWM Techniques and charge balance control methods for cascaded multilevel converters" in proc. CCECE, Canada,pp. 243-246.

[2] K.Ding, K.W.E. cheng, and Y.P.Zou, (2012) "Analysis of asymmetric modulation methods for cascaded multilevel inverter" IET Power electron. vol. 5, no. 1, pp. 74-85.

[3] J. Napoles, A. J. Watson, and J. J Padilla, (2013) "Selective harmonic mitigation technique for cascaded H-bridge converter with non equal dc link voltages"' IEEE Trans. Ind. Electron. vol. 60, no. 5, pp. 1963-1971.

[4] N. Farokhina, S.H. Fathi, N.Yousefpoor, and M.K.Bakshizadeh (2012)"Minimisation of total harmonic distortion in a cascaded multilevel inverter by regulating of voltages $\mathrm{dc}$ sources" IET Power Electron, vol. 5, no. 1, pp. 106-114. 
Superior Performances of Different New Multilevel Inverter Topology with Disparate Pulse Techniques

[5] S.Mekhilef, M.N. Abdul Kabir, and Z. Salam, (2013) "Digital control of three phase three-stage hybrid multilevel inverter" IEEE Trans. Ind. Inform. vol. 9, no. 2, pp. 719-727.

[6] K. Ramani and A. Krishan, (2010) "New hybrid multilevel inverter fed induction motor drive-A diagnostic study" International Review of Electrical Engineering (IREE), vol. 5, no. 6, part. A, pp. 2562-2569.

[7] R. Kumar and B. Singh, (2014) "Solar PV array fed Cuk converter-VSI controlled BLDC motor drive for water pumping," 6th IEEE Power India Int. Conf. (PIICON), 5-7 Dec. pp. $1-7$.

[8] B. Singh and V. Bist, (2015) "A BL-CSC Converter-Fed BLDC Motor Drive with Power Factor Correction," IEEE Trans. Ind. Electron., vol. 62, no. 1, pp. 172-183.

[9] Rajan Kumar and Bhim Singh, (2014) "Buck-boost converter fed BLDC motor drive for solar PV array based water pumping," in IEEE International Conference on Power Electronics, Drives and Energy Systems (PEDES), 16-19 Dec. pp.1-6.

[10] Ali Reza Reisi, Mohammad Hassan Moradi and Shahriar Jamasb, (2013) "Classification and Comparison of Maximum Power Point Tracking Techniques for Photovoltaic System: A review," Renewable and Sustainable Energy Reviews, vol. 19, pp. 433-443.

[11] E. Babaei and S. H. Hosseini., (2009) "New cascaded multilevel inverter topology with minimum number of switches,"Energy Conversion and Management, Vol. 50, No. 11, pp.2761-2767.

[12] E. Babaei, M. F. Kangarlu, and M. Sabahi, (2014) "Extended multilevel converters: An attempt to reduce the number of independent DC voltage sources in cascaded multilevel converters," IET Power Electron., Vol. 7, No. 1, pp. 157-166.

[13] K. K. Gupta and S. Jain. (2012) "Topology for multilevel inverters to attain maximum number of levels from given DC sources," IET Power Electron., Vol. 5, No. 4, pp. 435446.

[14] M. F. Kangarlu and E. Babaei, (2013) "Cross-switched multilevel inverter: an innovative topology,” IET Power Electron., Vol. 6, No. 4, pp. 642-651.

[15] Y. Ounejjar, K. Al-Haddad, and L. A. Dessaint, (2012) "A novel six-band hysteresis control for the packed U cell seven-level converter: Experimental validation," IEEETrans. Ind. Electron., Vol. 59, No. 10, pp. 3808-3816.

[16] K. K. Gupta, A. Ranjan, P. Bhatnagar, L. K. Sahu, and S.Jain, (2016) "Multilevel inverter topologies with reduced device count: A review," IEEE Trans. Power Electron., Vol. 31, No. 1, pp. 135-151.

[17] Shukla, A.; Ghosh, A.; Joshi, A. (2011) Hysteresis Modulation of Multilevel Inverters. IEEE Trans. Power Electron., 26, 1396-1409. [CrossRef]

[18] Rahim, N.A.; Selvaraj, J.; Chaniago, K. (2009) A novel PWM multilevel inverter for PV application. IEICE Electron. Express. 6, 1105-1111. [CrossRef]

[19] Rekioua, D.; Matagne, E. (2012) Optimization of Photovoltaic Power Systems, Modelization, Simulation and Control; Springer: London, UK, pp. 31-87.

[20] Rathore, A.K.; Holtz, J.; Boller, T. (2010) Synchronous optimal pulse width modulation for low-switching-frequency control of medium-voltage multilevel inverters. IEEE Trans. Ind. Electron. 57, 2374-2381.

[21] Rathore, A.; Holtz, J.; Boller, T. (2013) Generalized optimal pulse width modulation of multilevel inverters for low-switching-frequency control of medium-voltage high-power industrial ac drives. IEEE Trans. Ind. Electron. 60, 4215-4224. [CrossRef]

[22] Karthikeyan, D.; Krishnasamy, V.; Sathik, M.A.J. (2018) Development of a switched diode asymmetric multilevel inverter topology. J. Power Electron. 18, 418-431. 